\title{
Teor de nitrato em alface cultivada em sistemas hidropônico e convencional
}

\author{
Elisabete R. Yonamini Beninni' ${ }^{1}$ Hideaki Wilson Takahashi; Carmen S.V.J. Neves; Inês Cristina de B. Fonseca \\ UEL, Depto. Agronomia, C. Postal 6001, 86.051-990, Londrina - PR. E-mail: beninni@sercontel.com.br
}

\section{RESUMO}

O monitoramento do teor de nitrato nos alimentos é importante, uma vez que poderão ser formados compostos prejudiciais à saúde humana e animal após sua ingestão. Com o objetivo de avaliar o teor de nitrato presente em alface, foram coletadas e analisadas as folhas de alface crespa comercializada no Município de Londrina, cultivada em sistemas hidropônico e convencional. Os valores encontrados variaram entre 26 e $2.568 \mathrm{mg} . \mathrm{kg}^{-1}$ de peso fresco, sendo que as plantas cultivadas em sistema hidropônico apresentaram teores superiores em relação às cultivadas em sistema convencional, porém abaixo do limite máximo de nitrato permitido para alface, na Europa.

\begin{abstract}
Level of nitrate in lettuce cultivated in hydroponic and conventional systems

The control of the nitrate level in foods is important because this substance may be harmful to human and animal health. The aim of this work was to evaluate nitrate levels in lettuce produced in hydroponic and conventional systems and commercialized in Londrina, Brazil. The nitrate concentration ranged from 26 to 2,568 mg.kg-1 fresh weight. Hydroponic lettuce showed higher levels of nitrate but in all cases the level of nitrate was lower than the maximum allowed by the Comission of the European Communities.
\end{abstract}

Keywords: Lactuca sativa L., hydroponic.

Palavras-chave: Lactuca sativa L., hidroponia.

(Aceito para publicação em 26 de outubro de 2.001)

$\mathrm{O}$ homem é diariamente exposto à presença de nitrito e nitrato através de drogas, água e alimentos. Geralmente, suas quantidades são pequenas, não apresentando efeito prejudicial à saúde humana e animal (Maynard et al., 1976). Porém, quando os alimentos possuem alto teor de nitrato, sua qualidade nutricional é diminuída, devido aos compostos nocivos formados a partir de sua ingestão. Maiores prejuízos à saúde são causados pelo nitrito e nitrosaminas. O primeiro é produzido pela redução do nitrato, causando inibição do transporte de oxigênio pelo sangue, condição conhecida como metanemia e o segundo é cancerígeno (Walker, 1990).

Algumas plantas acumulam nitrato nas raízes e na parte aérea quando a absorção excede as suas necessidades metabólicas (Maynard et al., 1976), sendo encontrados altos teores nas folhas, especialmente no mesófilo, porém os pecíolos e talos são os locais de máxima acumulação (Maynard \& Barker, 1972). Por outro lado, os órgãos reprodutivos, frutos e sementes, são supridos com aminoácidos via floema (Blom-Zandstra,
1989), possuindo baixos teores de nitrato (Pate, 1980).

Entre os alimentos consumidos pelo homem, os vegetais representam entre 72 e $94 \%$ da ingestão diária de nitrato (Santamaria, 1997). Para a Organização Mundial da Saúde, a ingestão diária aceitável de nitrato, sem risco para a saúde, é 3,65 mg.dia ${ }^{-1}$ por $\mathrm{kg}$ de peso vivo (Escoín-Peña et al., 1998).

A alface possui grande habilidade em acumular nitrato em suas folhas (Roorda van Eysinga, 1984) e, como são a parte consumida, existe grande interesse em se monitorar o teor de nitrato nestas plantas. $\mathrm{O}$ acúmulo depende de vários fatores como intensidade luminosa, temperatura (Cantliffe, 1972; Kanaan \& Economakis, 1992), manejo, quantidade e fonte de fertilizantes nitrogenados (Gunes et al., 1994; Pavlovic et al., 1997; Urrestarazu et al., 1998), genótipos (Blom-Zandstra \& Eenink, 1986; Behr \& Wiebe, 1992; Weimin et al., 1998) e a disponibilidade de molibdênio, que influencia a atividade da redutase do nitrato, enzima responsável pela redução do nitrato a nitrito no processo de assimilação de nitrogênio pela planta (Marschner, 1986).

O nitrato presente nos vegetais pode ter origem do nitrato adicionado como fertilizante ou formado, no substrato, pela mineralização ou nitrificação (Maynard et al., 1976). Richardson \& Hardgrave (1992) concluíram que diferentes fontes de nitrogênio aplicadas no solo não influenciaram o teor de nitrato nas plantas.

Como em sistema hidropônico é comum a utilização de fonte nítrica, acredita-se que esse cultivo proporcione plantas de alface com alto teor de nitrato (Luo et al., 1993). Assim, o objetivo do presente trabalho foi avaliar o teor de nitrato em folhas de alface crespa, comercializada no Município de Londrina, Paraná, provenientes de sistemas de cultivo hidropônico e convencional.

\section{MATERIAL E MÉTODOS}

As amostras de alface crespa foram coletadas em 15 pontos de venda no Município de Londrina, entre 28/08/00 e 15/09/00. Coletaram-se 32 amostras de

\footnotetext{
${ }^{1}$ Bolsista Capes
} 
Tabela 1. Teores de nitrato (mg.kg ${ }^{-1}$ peso fresco) em alface cultivada em sistemas convencional e hidropônico, comercializada em Ago/Set de 2000, no Município de Londrina. Londrina, UEL, 2.000.

\begin{tabular}{|c|c|c|c|c|c|c|c|}
\hline \multirow{2}{*}{ Sistema de Cultivo } & \multirow{2}{*}{$\mathbf{n}$} & \multirow{2}{*}{ Média } & \multirow{2}{*}{ Máximo } & \multirow{2}{*}{ Mínimo } & \multirow{2}{*}{$\begin{array}{l}\text { Desvio } \\
\text { padrão }\end{array}$} & \multicolumn{2}{|c|}{$\begin{array}{c}\text { Intervalo de confiança } \\
\text { da média }\end{array}$} \\
\hline & & & & & & $\begin{array}{c}\text { Lim. } \\
\text { inferior }\end{array}$ & $\begin{array}{c}\text { Lim. } \\
\text { superior }\end{array}$ \\
\hline Convencional & 30 & 939 & 1.910 & 26 & 613 & 710 & 1.168 \\
\hline Hidropônico & 32 & 1.588 & 2.568 & 471 & 560 & 1.386 & 1.790 \\
\hline
\end{tabular}

Tabela 2. Teor médio de nitrato (mg.kg-1 peso fresco) em alface cultivada em sistemas convencional e hidropônico, comercializada em Ago/Set de 2001, no Município de Londrina. Londrina, UEL, 2.001.

\begin{tabular}{lcc}
\hline \multicolumn{1}{c}{ Sistema de cultivo } & Teor médio de nitrato & Teor padrão* $^{*}$ \\
\hline Convencional & $939 \mathrm{~b} \mathrm{~B}^{1}$ & $4.500 \mathrm{~A}$ \\
Hidropônico & $1.588 \mathrm{a} \mathrm{B}$ & $4.500 \mathrm{~A}$ \\
\hline
\end{tabular}

${ }^{(*)}$ Valor máximo de nitrato permitido em alface, através da legislação européia.

${ }^{(1)}$ Médias seguidas de mesma letra minúscula na coluna e maiúscula na linha, não diferem entre si, no nível de $1 \%$, pelo teste t.

plantas de alface produzidas em sistema hidropônico e 30 amostras de alface produzidas em sistema convencional, de acordo com o tamanho amostral determinado por um experimento prévio.

As folhas de alface foram pesadas, lavadas em águas corrente, destilada e deionizada, colocadas para secar em estufa com circulação de ar a $60^{\circ} \mathrm{C}$ até peso constante e, após, foram moídas. Em subamostras secas foi determinado o teor de nitrato no laboratório de Solos da UEL, através da metodologia descrita por Cataldo et al. (1975), com 3 repetições laboratoriais para cada amostra.

Utilizou-se o teste $t$ para as amostras independentes com variâncias homogêneas, para comparar as médias dos teores de nitrato entre alface cultivadas em sistemas hidropônico e convencional. Compararam-se também as médias com o limite máximo de nitrato permitido na Europa de $4.500 \mathrm{mg} \cdot \mathrm{kg}^{-1}$ peso fresco (Escoín-Peña et al., 1998), pelo teste $\mathrm{t}$ para uma média (Downing \& Clark, 1998).

\section{RESULTADOS E DISCUSSÃO}

$\mathrm{Na}$ alface produzida em hidroponia, o teor médio de nitrato foi $1.588 \mathrm{mg} . \mathrm{kg}^{-1}$ peso fresco, com valores máximo e mínimo de 2.568 e $471 \mathrm{mg} . \mathrm{kg}^{-1}$ peso fresco, respectivamente, e desvio padrão de
$560 \mathrm{mg} \cdot \mathrm{kg}^{-1}$ peso fresco. No cultivo convencional, os valores correspondentes foram 939; $1.910 ; 26$ e $613 \mathrm{mg} . \mathrm{kg}^{-1}$ peso fresco (Tabela 1).

$\mathrm{O}$ intervalo de confiança da média demonstra, com $95 \%$ de confiança, que o teor médio de nitrato em alface produzida em sistema hidropônico está entre 1.386 e $1.790 \mathrm{mg} \cdot \mathrm{kg}^{-1}$ peso fresco e na alface cultivada em sistema convencional entre 710 e $1.168 \mathrm{mg} \cdot \mathrm{kg}^{-1}$ peso fresco (Tabela 1).

$\mathrm{O}$ teor médio de nitrato em alface produzida em sistema hidropônico foi superior ao encontrado na alface produzida em sistema convencional ( $p<0,01)$, apresentando a média de $1.588 \mathrm{mg} . \mathrm{kg}^{-1}$ peso fresco no cultivo hidropônico e 939 mg. $\mathrm{kg}^{-1}$ peso fresco no cultivo convencional (Tabela 2). Pelo regulamento europeu o limite máximo de nitrato permitido em alface é $4.500 \mathrm{mg} \cdot \mathrm{kg}^{-1}$ peso fresco, quando o cultivo ocorre no inverno e $2.500 \mathrm{mg} \cdot \mathrm{kg}^{-1}$ peso fresco no verão (Escoín-Peña et al., 1998). Quando comparado com o limite de 4.500 mg. $\mathrm{kg}^{-1}$ peso fresco, o teor médio de nitrato em alface cultivado no sistema hidropônico foi inferior (Tabela 2). $\mathrm{O}$ máximo valor obtido $\left(2.567 \mathrm{mg} \cdot \mathrm{kg}^{-1}\right.$ peso fresco), no cultivo hidropônico, não foi superior ao estabelecido pelo regulamento europeu.

Verificou-se que $36,7 \%$ das amostras de alface produzidas em sistema convencional possuíam plantas com os teores de nitrato inferior a $500 \mathrm{mg} \cdot \mathrm{kg}^{-1}$ e $20 \%$ com teores entre 1.500 e 2.000 mg. $\mathrm{kg}^{-1}$. Na alface produzida em sistema hidropônico, $65,5 \%$ referiam-se às plantas com teores entre 1.000 e 2.000 mg. $\mathrm{kg}^{-1}$ e $6 \%$ com teores superiores à $2.500 \mathrm{mg} \cdot \mathrm{kg}^{-1}$, todos com base no peso fresco (Figura 1). Tais variações podem estar relacionadas a diferenças na absorção, assimilação e translocação do nitrato (Maynard et al., 1976) ou podem ter sofrido influência dos fertilizantes utilizados pelos diferentes produtores (Forlani et al., 1997; Lyons et al., 1994). Resultados semelhantes foram obtidos por Lyons et al. (1994), que obtiveram teor médio de nitrato de $465 \mathrm{mg} . \mathrm{kg}^{-1}$ peso fresco em alface produzida em sistema hidropônico e de $213 \mathrm{mg} \cdot \mathrm{kg}^{-1}$ peso fresco em alface cultivada em sistema convencional. Da mesma forma, Forlani et al. (1997), estudando o teor de nitrato em vegetais comercializados na Itália, encontraram, em alface, variação de 10 e $3.680 \mathrm{mg} . \mathrm{kg}^{-1}$ peso fresco. Nos estudos realizados por Fytianos \& Zarogiannis (1999), a variação foi de 8 e $808 \mathrm{mg} \cdot \mathrm{kg}^{-1}$ peso fresco e Escoín-Peña et al. (1998) encontraram entre $10 \mathrm{e}$ $1.243 \mathrm{mg} . \mathrm{kg}^{-1}$ peso fresco.

Em folhas de espinafre, Cantliffe (1972) verificou que o teor de nitrato aumentou pela adição do nitrogênio ao solo e pela redução da intensidade luminosa. O maior acúmulo de nitrato, em baixa intensidade luminosa, pode ser o resultado de decréscimo na atividade da redutase do nitrato (Cantliffe, 1972). Outra hipótese é de que o nitrato poderia servir como regulador osmótico, acumulando-se no vacúolo, compensando a falta de carboidratos solúveis, sendo o teor de nitrato inversamente proporcional ao de ácidos orgânicos e açúcares (Behr \& Wiebe, 1992; BlomZandstra, 1989; Urrestarazu et al., 1998). 


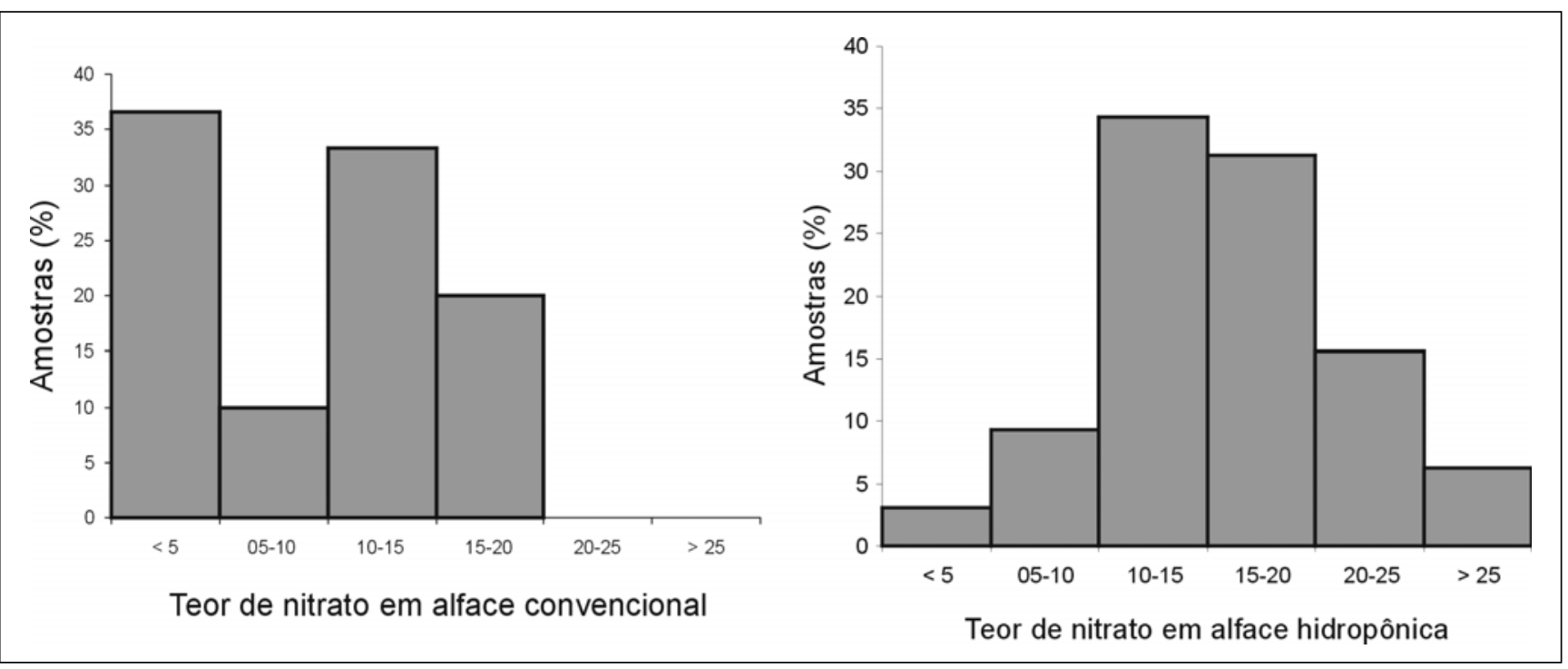

Figura 1. Distribuição de freqüência das amostras (\%) de alface produzidas nos sistemas convencional e hidropônico por classe de teores de nitrato ( $10^{2} \mathrm{mg} \cdot \mathrm{kg}^{-1}$ peso fresco), comercializada em Ago/Set de 2000, no Município de Londrina. Londrina, UEL, 2.000.

Kanaan \& Economakis (1992) também constataram a influência das condições climáticas sobre o teor de nitrato em alface. Em condições de alta intensidade luminosa e temperatura, obtiveram plantas mais pesadas e com menos nitrato. Consequentemente, a época do ano em que a cultura é colhida possui efeito marcante no acúmulo de nitrato (Roorda van Eysinga, 1984). Petersen \& Stoltze (1999) verificaram, claramente, maior teor de nitrato quando o cultivo ocorreu no inverno e menor durante o verão.

No presente experimento, as amostras foram coletadas no final do inverno, o que pode ter influenciado o teor de nitrato das plantas, devido à menor intensidade luminosa da época. Para a comprovação disso, em nossas condições, há necessidade de realização do mesmo estudo durante o verão.

A ingestão diária estimada de nitrato varia de $43 \mathrm{mg}$. $\mathrm{dia}^{-1}$ na Noruega até $367 \mathrm{mg}$. dia ${ }^{-1}$ para uma dieta vegetariana, nos Estados Unidos (Walker, 1990). A Organização Mundial da Saúde estabeleceu o limite de 3,65 mg. dia ${ }^{-1}$ por kg de peso vivo para a ingestão diária admissível de nitrato sem risco para a saúde (Escoín-Peña et al, 1998). Considerando um adulto de $60 \mathrm{~kg}$ e o teor médio de nitrato na alface produzida em sistema hidropônico de $1.588 \mathrm{mg} \cdot \mathrm{kg}^{-1}$ peso fresco, a ingestão diária de alface para atingir o nível crítico, seria de 138 g, o que corresponde ao consumo de meia cabeça de alface, pois o peso médio da alface hidropônica, neste trabalho, foi 271,3 g (considerando somente as folhas).

Apesar dos maiores valores obtidos na alface cultivada em sistema hidropônico, estes não foram superiores ao estabelecido pela legislação européia, considerando-se de boa qualidade os produtos comercializados no Município, no que se refere ao teor de nitrato.

\section{LITERATURA CITADA}

BEHR, U.; WIEBE, H.J. Relation between photosynthesis and nitrate content of lettuce cultivars. Scientia Horticulturae, v. 49, n. 3-4, p. 175-179, 1992.

BLOM-ZANDSTRA, M. Nitrate accumulation in vegetables and its relationship to quality. Annals of Applied Biology, v. 115, n. 3, p. 553-561, 1989. BLOM-ZANDSTRA, M.; EENINK, A.H. Nitrate concentration and reduction in different genotypes of lettuce. Journal of the American Society for Horticulture Science, v. 111, n. 6, p. 908-911, 1986. CANTLIFFE, D.J. Nitrate accumulation in spinach grown under different light intensities. Journal of the American Society for Horticulture Science, v. 97, n. 2, p. 152-154, 1972.

CATALDO, D.A.; HAROON, M.; SCHRADER, L.E.; YOUNGS, V.L. Rapid colorimetric determination of nitrate in plant tissue by nitration of salicylic acid. Communications in Soil Science and Plant Analysis, v. 6, n. 1, p. 71-80, 1975.

DOWNING, D.; CLARK, J. Estatística aplicada. Trad. A.A. Farias. São Paulo: Saraiva, 1998. p. 235-264. Tradução de Business Statistics.

ESCOÍN-PEÑA, M.C.; IBAÑEZ, M.A.C.; SANTAMARTA, A.A.; LAZARO, R.C. Contenido de nitratos en lechugas y espinacas frescas. Alimentaria, n. 298, p. 37-41, 1998.
FORLANI, L.; GRILLENZONI, S.; ORI, E.; RESCA, P. Nitrate levels in vegetables that may be eaten raw. Italian Journal of Food Science, v. 9, n. 1, p. 65-69, 1997.

FYTIANOS, K.; ZAROGIANNIS, P. Nitrate and nitrite accumulation in fresh vegetables from Greece. Bulletin of Environmental Contamination and Toxicology, v. 62, n. 3, p. 187-192, 1999.

GUNES, A.; POST, W.N.K.; KIRKBY, E.A.; AKTAS, M. Influence of partial replacement of nitrate by amino acid nitrogen or urea in the nutrient medium on nitrate accumulation in NFT grown winter lettuce. Journal of Plant Nutrition, v. 17, n. 11, p. 1.929-1.938, 1994.

KANAAN, S.S.; ECONOMAKIS, C.D. Effect of climatic conditions and time of harvest on growth and tissue nitrate content of lettuce in nutrient film culture. Acta Horticulturae, n. 323, p. 75-80, 1992. LUO, J.; LIAN, Z.; YAN, X. Urea transformation and the adaptability of three leafy vegetables to urea as a source of nitrogen in hydroponic culture. Journal of Plant Nutrition, v. 16, n. 5, p. 797-812, 1993.

LYONS, D.J.; RAYMENT, G.E; NOBBS, P.E.; McCALLUM, L.E. Nitrate and nitrite in fresh vegetables from Queensland. Journal of the Science of Food and Agriculture, v. 64, n. 3, p. 279-281, 1994.

MARSCHNER, H. Mineral nutrition of higher plants. London: Academic Press, 1986, 674 p.

MAYNARD, D.N.; BARKER, A.V. Nitrate content of vegetable crops. HortScience, v. 7, n. 3, p. 224-226, 1972.

MAYNARD, D.N; BARKER, A.V.; MINOTTI, P.L.; PECK, N.H. Nitrate accumulation in vegetables. Advances in Agronomy, v. 28, p. 71118, 1976.

PATE, J.S. Transport and partitioning of nitrogenous solutes. Annual Review of Plant Physiology, v. 31, p. 313-340, 1980.

PAVLOVIC, R.M.; STEVANOVIC, D.R.; KRESOVIC, M.M. Effect of growing method and lettuce fertilization on changes of nitrate content in leaf. Acta Horticulturae, n. 462, p. 885-889, 1997. 
PETERSEN, A.; STOLTZE, S. Nitrate and nitrite in vegetables on the Danish market: content and intake. Food Additives and Contaminants, v. 16, n. 7, p. 291-299, 1999.

RICHARDSON, S.J.; HARDGRAVE, M. Effect of temperature, carbon dioxide enrichment, nitrogen form and rate of nitrogen fertiliser on the yield and nitrate content of two varieties of glasshouse lettuce. Journal of the Science Food and Agriculture, v. 59, n. 3, p. 345-349, 1992.
ROORDA Van EYSINGA, J.P.N.L. Nitrate and glasshouse vegetables. Fertilizer Research, v. 5 , p. 149-156, 1984.

SANTAMARIA, P. Contributo degli ortaggi all' assunzione giornaliera di nitrato - nitrito e nitrosamina). Industrie-Alimentari, v. 36, n. 364, p. 1.329-1.334, 1997.

URRESTARAZU, M.; POSTIGO, A.; SALAS, M.; SÁNCHEZ, A.; CARRASCO, G. Nitrate accumulation reduction using chloride in the nutrient solution on lettuce growing by NFT in semiarid climate conditions. Journal of Plant Nutrition, v. 21, n. 8, p. 1.705-1.714, 1998.
WALKER, R. Nitrates, nitrites and Nnitrosocompounds - review of the occurrence in food and diet and the toxicological implications. Food Additives and Contaminants, v. 7, n. 6, p. 717-768, 1990.

WEIMIN, Z.; SHIJUN, L.; LIHONG, G; ZHONGYANG, H.; DABIAO, Z. Genetic diversity of nitrate accumulation in vegetable crops. Acta Horticulturae, n. 467, p. 119-126, 1998.

CALVETE, E.O.; KÄMPF ,A.N.; SUZIN, M. Concentração de sacarose no enraizamento in vitro de morangueiro. Horticultura Brasileira, Brasília, v. 20, n. 2, p. 186-191, junho 2.002 .

\section{Concentração de sacarose no enraizamento in vitro de morangueiro ${ }^{1}$}

\section{Eunice Oliveira Calvete ${ }^{2}$; Atelene Normann Kämpf ${ }^{3}$; Marilei Suzin ${ }^{2}$}

${ }^{2}$ UPF, C. Postal 611, 99.001-070 Passo Fundo-RS; ${ }^{3}$ UFRGS, Departamento de Horticultura e Silvicultura, C. Postal 776, 91.501-970, Porto Alegre-RS. E-mail:calveteu@upf.tche.br

\section{RESUMO}

O morangueiro é uma espécie de propagação vegetativa, o que explica a disseminação de doenças, quando utiliza-se plantas infestadas. Uma forma de eliminar as viroses é através da cultura de meristemas. Uma das etapas mais delicadas do processo de micropropagação é a transferência das mudas para condições ex vitro. Para garantir sucesso durante a aclimatização, faz-se necessário otimizar todas as fases do cultivo. Entre essas, encontra-se a etapa de enraizamento. Esse trabalho foi realizado nos Laboratórios da UFRGS e da UPF com o objetivo de quantificar o efeito da concentração de sacarose no meio de cultivo in vitro, na fase de enraizamento. Mudas da cultivar Campinas foram selecionadas na etapa de multiplicação e repicadas para o meio básico "MS" (Murashige \& Skoog) acrescido de $0,005 \mathrm{mg} . \mathrm{L}^{-1}$ de BAP (Benzinoaminopurina) e diferentes concentrações de sacarose $\left(0 ; 15 ; 30 ; 45\right.$ e 60 g.L. $\left.\mathrm{L}^{-1}\right)$. O delineamento experimental foi o de blocos casualizados com nove repetições. Cada parcela constou de cinco plantas por frasco, perfazendo um total de 45 unidades amostrais. Nessa etapa foram avaliadas as massas fresca e seca das folhas e raízes (mg). A partir dessas foi calculado o conteúdo de água nos tecidos. Observou-se que na ausência de sacarose não houve desenvolvimento da raiz in vitro. Plantas produzidas na concentração de 45 g. $\mathrm{L}^{-1}$ de sacarose, apresentaram maior enraizamento. Dessa forma, mudas de morangueiro Campinas apresentaram baixa capacidade fotossintética, respondendo como plantas mixotróficas ou heterotróficas.

Palavras-chave: Fragaria X ananassa Duch., biomassa, sacarose, micropropagação.

\section{ABSTRACT \\ Sucrose concentration on in vitro rooting of strawberry plants}

The vegetative propagation of strawberry plants allows dissemination of plant pathogens when infected plants are used. To avoid such pathogen transmission, especially viruses, plant merystem growing in vitro is usual. Transfer of micropropagated seedlings to ex vitro conditions, however, is a delicate process. Successful plant adaptation to ambient depends on optimum growing conditions including the rooting phase. This research was conducted at the Universidade Federal do Rio Grande do Sul and Universidade de Passo Fundo (Brazil). The effect of sucrose concentration was quantified in the culture medium over rooting of strawberry plants. Seedlings of cv. Campinas were selected during multiplication and transferred to an "MS" (Murashige \& Skoog) basic medium amended with BAP $\left(0.005 \mathrm{mg} \mathrm{L}^{-1}\right)$ and different sucrose amounts $(0 ; 15 ; 30$; 45 , and $\left.60 \mathrm{~g} \mathrm{~L}^{-1}\right)$. The experimental units were arranged according to a randomized block design with nine replicates, each replicate being a pot with five plants. The fresh and dry weight of leaves and roots were determined and used to calculate the content of water in plant tissues. While lack of sucrose resulted in no rooting, the concentration of $45 \mathrm{~g} \mathrm{~L}^{-1}$ provided the best root growth. Therefore, Campinas strawberry seedlings showed low photosynthetic capacity, behaving as mixotrophic or heterotrophic plants.
Keywords: Fragaria X ananassa Duch., biomass, sucrose, micropropagation.

\section{(Aceito para publicação em 15 de fevereiro de 2.002)}

$\mathrm{N}$ a horticultura, a técnica de cultura de tecidos tem encontrado aplicações práticas e comerciais. $\mathrm{O}$ cultivo in vitro, em especial a cultura de meristemas, pode resultar na multiplicação mais eficiente, com obtenção de materiais de melhor qualidade (Minami, 1991).
Uma das fases mais críticas na micropropagação de morangueiro, e na maioria das espécies vegetais, é a transição do meio heterotrófico para o autrotrófico (Desjardins et al., 1987). Alta taxa de sobrevivência, obtida em plantas aclimatizadas ex vitro, depende do corre- to tratamento providenciado durante o processo da transição in vitro para in vivo.

Para a formação das raízes é necessário energia. Esta pode ser oriunda da fotossíntese ou de outra fonte de açúcar. O carbono exógeno no meio de cultivo serve como fonte de energia, influ-

\footnotetext{
${ }^{1}$ Parte integrante da tese de Doutorado do primeiro autor, realizada no Departamento de Horticultura da UFRGS.
} 